\title{
Push-Out Bond Strength of Quartz Fiber Posts Luted with Self-Adhesive and Conventional Resin Cements
}

\section{Resistencia de unión de postes de fibra de cuarzo cementados con cementos resinosos autoadhesivos y/o convencional}

a la dentina intra-radicular

Luiz Clóvis Cardoso Vieira DDS, MSD, PhD1; Élito Araújo DDS, MSD, PhD1; Luiz Narciso Baratieri DDS,MSD, PhD'; Juan Carlos Ramírez Barrantes DDS, MSD, PhD²

1. Dental School, Federal University of Santa Catarina, Brazil.

2. Faculty of Dentistry University of Costa Rica, Costa Rica.

Correspondence to: Dr. Juan Carlos Ramírez Barrantes - juan.ramirez@ucr.ac.cr

Received: 18-V-2016

Accepted: 6-VI-2016

Published Online First: 9-VI-2016

DOI: http://dx.doi.org/10.15517/ijds.v0i0.24995

ABSTRACT

The aim of this study was to evaluate the influence of the resin cement on push-out bond strength of quartz fiber posts to intraradicular dentin. Fifty-six single-rooted human teeth were selected. After removing the crown, roots were endodontically treated and the dowel spaces were prepared with \# 2 post drills of DT Ligth $\circledast$ SL Post System (VDW $®$ ). The specimens were randomly divided into four groups $(n=14)$. Group 1: RelyX'M Unicem (3M ESPE), Group 2: Clearfil TM SA Cement (Kuraray), Group 3: Bifix SE (Voco), and G4 RelyXTM ARC (3M ESPE). After $24 \mathrm{~h}, 12$ specimens of each group were sectioned in 6 slices with $1 \mathrm{~mm}$ of thickness, two of each radicular third. The push-out test was conducted in an Instron machine at $0.5 \mathrm{~mm} / \mathrm{min}$. Data were submitted to ANOVA and Bonferroni test. Fractured specimens were observed at $25 \mathrm{X}$ to evaluate the types of failures. Two specimens of each group were processed for SEM evaluation. The Mean values (MPa) for groups 1, 2, 3 and 4 were respectively: 11.06, 8.85, 8.37 and 13.36. All experimental groups showed higher values of resistance in the cervical third, while the lowest were in the apical third. Adhesive failures between cement and dentin $(46.87 \%)$ prevailed, followed by mixed failures (45.15\%). SEM photomicrographs illustrating the interface formed between the self-adhesive resin cements and dentin showed an interface without the formation of a hybrid layer. G4 showed the formation of a thick and homogeneous hybrid layer with resin tags. The conventional resin cement associated with a three-step adhesive system displayed the higher bond strength to intraradicular dentin, when compared to the different self-adhesive resin cements.

\section{KEYWORDS}

Intraradicular dentin; Push-out bond strength; Resin cement; Scanning electron microscope. 


\section{RESUMEN}

El objetivo de este estudio fue evaluar la influencia del cemento de resina en la resistencia de unión de postes de fibra de cuarzo a la dentina intra-radicular. Se seleccionaron cincuenta y seis dientes humanos uniradiculares. Posterior a la remoción de la corona, las raíces fueron tratadas endodónticamente y los espacios para la colocación de los endopostes se prepararon con la broca $n^{0} 2$ del Sistema DT Ligth $®$ SL (VDW®). Las muestras se dividieron en cuatro grupos ( $n=14)$. Grupo 1: RelyX TM Unicem (3M ESPE), Grupo 2: Clearfil TM SA (Kuraray), Grupo 3: Bifix SE (Voco), y G4 RelyX TM ARC (3M ESPE). Después de 24 h, 12 especímenes de cada grupo se seccionaron en 6 discos de dentina de $1 \mathrm{~mm}$ de espesor, dos de cada tercio radicular. La prueba de resistencia de unión se llevó a cabo en una máquina Instron a 0,5 mm/min. Los datos fueron sometidos a la prueba de ANOVA y Bonferroni. Todas las muestras post-ensayo fueron observadas a 25X para evaluar los tipos de fallas. Dos muestras de cada grupo fueron procesadas para evaluación en microsocpía electrónica de barrido (MEB). Los valores medios (MPa) para los grupos 1, 2, 3 y 4 fueron, respectivamente: 11,06, 8,85, 8,37 y 13,36. Todos los grupos experimentales mostraron valores más altos de resistencia en el tercio cervical, mientras que Ios más bajos estaban en el tercio apical. Las fallas de adhesión entre el cemento y la dentina $(46,87 \%)$ prevalecieron, seguido de fallas mixtas (45.15\%). Las fotomicrografías de SEM que ilustran la interfaz formada entre los cementos de resina autoadhesivos y dentina mostraron una interfaz sin la formación de una capa híbrida. G4 mostró la formación de una capa híbrida de espesor continuo y homogénea con la presencia de tags resinosos. El cemento de resina convencional asociado con un sistema de adhesivo de tres pasos presentó una mayor resistencia de unión a la dentina intra-radicular, cuando se compara con los diferentes cementos de resina autoadhesivos utilizados.

\section{PALABRAS CLAVE}

Dentina intra-radicular; Resistencia de unión; Cemento resinoso; Microscopía electrónica de barrido.

\section{INTRODUCTION}

The restoration of endodontically treated teeth with fiber-reinforced composite posts has been studied intensively using bond strength testing of resin cements to the post surface $(1,2)$ as well as to the root canal dentin (3-7).

Despite major simplifications in dental adhesion, bonding to intra-radicular dentin remains an unpredictable goal (8). Bonding to root canal dentin is hampered by limited visibility, anatomical features, a comparably high configuration factor inside the root canal, and was found to be less effective than bonding to coronal dentin (1-2).

Interest has been increasingly focused on the use of self-adhesive cements (9). These systems were designed with the purpose of combining the favorable characteristics of different cements into a single product, in an attempt to satisfy demands for simplification of luting procedures and supposedly leaving little room for application mistakes induced by technique-sensitivity (9-11). Self-adhesive cements are still relatively new and detailed information on their composition and adhesive properties is limited [8]. Rely X Unicem is one of the most extensively explained by the manufacturer (3M ESPE) and most investigated self-adhesive materials.

Although the basic adhesion mechanism should be the same for all self-adhesive cements, the variety of products that have been launched by different manufacturers possesses different chemical compositions that could influence their 
mechanical properties and bonding performances (12). Thus, the aim of this study was to investigate the push-out bond strength of different resin cements used for the cementation of epoxy resinbased fiber-posts with a industrial pre-coating. The null hypothesis tested was that no differences in bond strength are present among the tested resin cements.

\section{MATERIALS AND METHODS}

Fifty six extracted, single-rooted, cariesfree human teeth were selected for this study. The crown of each tooth was removed $1 \mathrm{~mm}$ above the CEJ by means of a slow speed diamond saw (Isomet, Buehler, Lake Bluff, IL, USA) under copious water cooling. The teeth were endodontically instrumented at a working length of $1 \mathrm{~mm}$ from the root apex. A crown-down technique was used with Gates Glidden drills \#2 to \#4 (Union Broach, New York, USA), stainless steel Flexofiles (Maillefer-Dentsply, Baillagues, Suíça) and 2,5\% sodium hypochlorite (Dermus, SC, Brasil). The master apical file was \#60. Gutta-percha cones (Dentsply-Maillefer, Tulsa, OK, EUA) were used for filling the root canal and cemented with an epoxyresin based sealer (AH Plus Jet, Dentsply-Maillefer, USA) according to the lateral condensation technique. Roots were coronally sealed with a temporary restorative material (Citodur, Septodont, Switzerland) and stored in a laboratory oven at $37^{\circ}$ $\mathrm{C}$ and $100 \%$ relative humidity.

After 24 hours, the root canals were enlarged using a low-speed drill provided by the manufacturer of the selected post system (DT Ligth $®$ SL, VDW, GmbH, Munich, Alemanha). All specimens were prepared by one practioner using a standardized procedure. The depth of the post space preparation was $12 \mathrm{~mm}$.

DT Ligth® SL posts size 2 (VDW, Alemanha) were tried and luted with the following four different resin cements, according to the manufacturer's instructions: 1. RelyX'TM Unicem (3M ESPE, Seefeld, Germany); 2. Clearfil ${ }^{T M}$ SA Cement (Kuraray Dental, Okayama, Japan); 3. Bifix SE (Voco, Cuxhaven, Germany); and 4. Rely XTM ARC (3M ESPE, Seefeld, Germany).

The cements were used in the dual-cured modality. After the first 5 min of auto-curing mode in which the post was loaded under finger pressure, additional $40 \mathrm{~s}$ of light polymerization through the translucent fiber post were performed (JETLITETM 2000, J. Morita, Irvine, USA; output: 600 mW/ cm2). The cement in excess was carefully removed with a spatula. Specimens were maintained for 24 $h$ at $37 \pm 1^{\circ} \mathrm{C}$.

\section{PUSH-OUT BOND STRENGTH TEST}

For the push-out bond strength test were used 12 specimens of each group. The portion of the root containing the fiber post was subsequently sectioned into six $1 \mathrm{~mm}$-thick slices with a diamond saw (Isomet, USA) under water cooling. The force of the cylindrical plunger of the Instron 4444 testing machine (Instron, Canton, MA, USA) was used to dislodge each inverted, truncated fiber post from the root dentin in an apical-coronal direction. A load $(0.5 \mathrm{~mm} / \mathrm{min}$ until failure) was then applied to the post surface that resulted in shear stresses along the cement/dentin - cement/ post interfaces. The retentive strength of the post fragment (MPa) was calculated by dividing the load at failure (Newton) by the interfacial area of the post segment (SL). The formula used for measuring the tronco-conical area was:

$\mathrm{SL}=\pi(\mathrm{R}+\mathrm{r})[(\mathrm{h} 2+(\mathrm{R}-\mathrm{r}) 2] 0.5$ where $\pi$ was equal to $3.14, R$ and $r$ were the coronal and the apical post radius respectively, and $h$ the root slice thickness. The diameters of the post and the thickness of the slice were individually measured using a digital caliper with $0.01 \mathrm{~mm}$ accuracy.

Failure modes were evaluated by a single operator under a stereomicroscope (Illuminated 
Magnifying Glass, Japan) at 25X magnification and classified as:

1. Adhesive (between the dentin and the cement); 2. Adhesive (between the post and the cement); 3. Cohesive (within the cement); 4. Cohesive (within the post); or 5. Mixed (adhesive and cohesive fractures occurred simultaneously). Representative stressed-to-failure slices were used for scanning electron microscopy (SEM) evaluation. Specimens were immersed in ascending ethanol solutions, gently air-dried, mounted on metallic stubs, gold-sputter coated (Bal-Tec SCD 005, Bal-tec Co., EUA) and observed under a scanning electron microscope (Phillips SEM XL30, Philips, Eindhoven, Netherlands).

\section{SEM EVALUATION}

The remaining 2 specimens of each group were processed for SEM observation (13). The specimens were mounted on aluminum stubs and sputter-coated with a $300-A^{\circ}$ gold layer. They were then observed under an SEM (Philips SEM XL 30 ) at an accelerating voltage of $15 \mathrm{kV}$. Descriptive comparisons between materials with respect to the morphologic characteristics of the post-resin cement-dentin interface were performed.

\section{STATISTICAL ANALYSIS}

The normal and equal distribution of the push-out bond strength data were first checked and verified by the Kolmogorov-Smirnov and Levene's test respectively. A two-way ANOVA was performed to verify the differences in push-out bond strengths between the tested luting cements $(p<0.05)$. A Bonferroni test was then executed for pos thoc comparisons $(p<0.001)$.

\section{RESULTS}

Bond strengths (mean and standard deviation) were affected by the type of resin cement used and the localization inside the root canal $(p<0.05)($ Table 1$)$.

RelyXTM ARC showed significantly higher push-out bond strength compared with selfadhesives cements $(p<0.05)$. Differences in bond strengths exist among the self-adhesive cements used for luting fiber posts $(p<0.05)$. RelyX'M Unicem exhibited significantly higher bond strengths than the other self-adhesive cements tested $(p<0.05)$. The push-out values of Clearfil ${ }^{\mathrm{TM}}$ SA were lower than those of RelyX ${ }^{\mathrm{TM}}$ Unicem $(p<0.05)$, but higher than Bifix SE that recorded the lowest push-out bond strength values.

Regarding the intra-radicular dentin, ANOVA test revealed a statistically significant difference between the values of bond strength of cements among the different radicular thirds $(p<0.005)$. It may be noted that within the same group, the bond strength values were significantly higher in cervical, followed by middle and apical thirds.

The failure modes recorded were mostly adhesive in nature, between dentin and cement (46.87\%) (Figure 1), followed by mixed failures $(45.15 \%)$ (Figure 1). Adhesive failures at the resin cement-post interface were shown (7.98\%). Among the mixed failures, the combination of adhesive failure between dentin and cement and at the post-resin cement interface occurred in a higher percentage (15.65\%) (Figure 1). Cohesive failures of cement or posts were observed only associated with other types of failures, showing no isolated cases. In the mixed failures involving cohesive failure of the post, it was possible to observe part of the epoxy resin that surrounds the fiber posts attached to the resin cement, exposing some quartz fibers (Figure 1).

SEM analyses of samples luted with RelyX'M Unicem reveals a continuous interface between the resin cement and dentin, demonstrating an interaction between the material and dentin. Most 
samples did not exhibit the formation of resin tags. continuous adaptation to the dentin surface, but However, in figure $2(A, B)$ is possible to observe the formation of few resin tags, suggesting that the cement penetrates into open dentinal tubules (without smear layer).

Moreover, the conventional dual resin cement RelyXTM ARC, associated with Scotch Bond Multipurpose Plus, revealed the formation of

Representative samples of Clearfil ${ }^{\mathrm{TM}} \mathrm{SA}$ a thick, continuous and homogeneous hybrid layer and Bifix SE showed that the cements have a with the presence of long resin tags (Figure 2).

Table 1. Bond strengths (mean and standard deviation).

\begin{tabular}{lcc}
\hline \multicolumn{1}{c}{ Groups } & Mean & SD \\
\hline G1 (RelyX'M Unicem) & $11,06^{\mathrm{a}}$ & 3,615 \\
G2 (ClearfilTM SA) & $8,85^{\mathrm{b}}$ & 3,240 \\
G3 (Bifix SE) & $8,37^{\mathrm{b}}$ & 2,978 \\
G4 (RelyXTM ARC) & $13,36^{\mathrm{c}}$ & 3,404 \\
\hline
\end{tabular}

Groups with different letters indicate statistically significant difference $(p<0,05)$.

Table 2. Bond Strenght (MPa) of the different groups and root thirds.

\begin{tabular}{lcccccc}
\hline & \multicolumn{2}{c}{ Cervical } & \multicolumn{2}{c}{ Middle } & \multicolumn{2}{c}{ Apical } \\
\cline { 2 - 6 } & Mean & SD & Mean & SD & Mean & SD \\
\hline G1 (RelyXTM Unicem) & $13,84^{\mathrm{a}}$ & 2,469 & $11,76^{\mathrm{a}}$ & 2,421 & $7,58^{\mathrm{a}}$ & 2,683 \\
G2 (Clearfil & & & \\
TM SA) & $11,67^{\mathrm{b}}$ & 2,854 & $8,63^{\mathrm{b}}$ & 1,853 & $6,24^{\mathrm{a}}$ & 2,318 \\
G3 (Bifix ${ }^{\mathrm{b} M}$ SE) & $10,74^{\mathrm{b}}$ & 2,419 & $8,88^{\mathrm{b}}$ & 2,291 & $5,50^{\mathrm{b}}$ & 1,248 \\
G4 (RelyXTM ARC) & $16,69^{\mathrm{c}}$ & 1,568 & $13,93^{\mathrm{c}}$ & 1,751 & $9,44^{\mathrm{c}}$ & 1,522 \\
\hline
\end{tabular}

Groups with different letters indicate statistically significant difference $(p<0,05)$. 

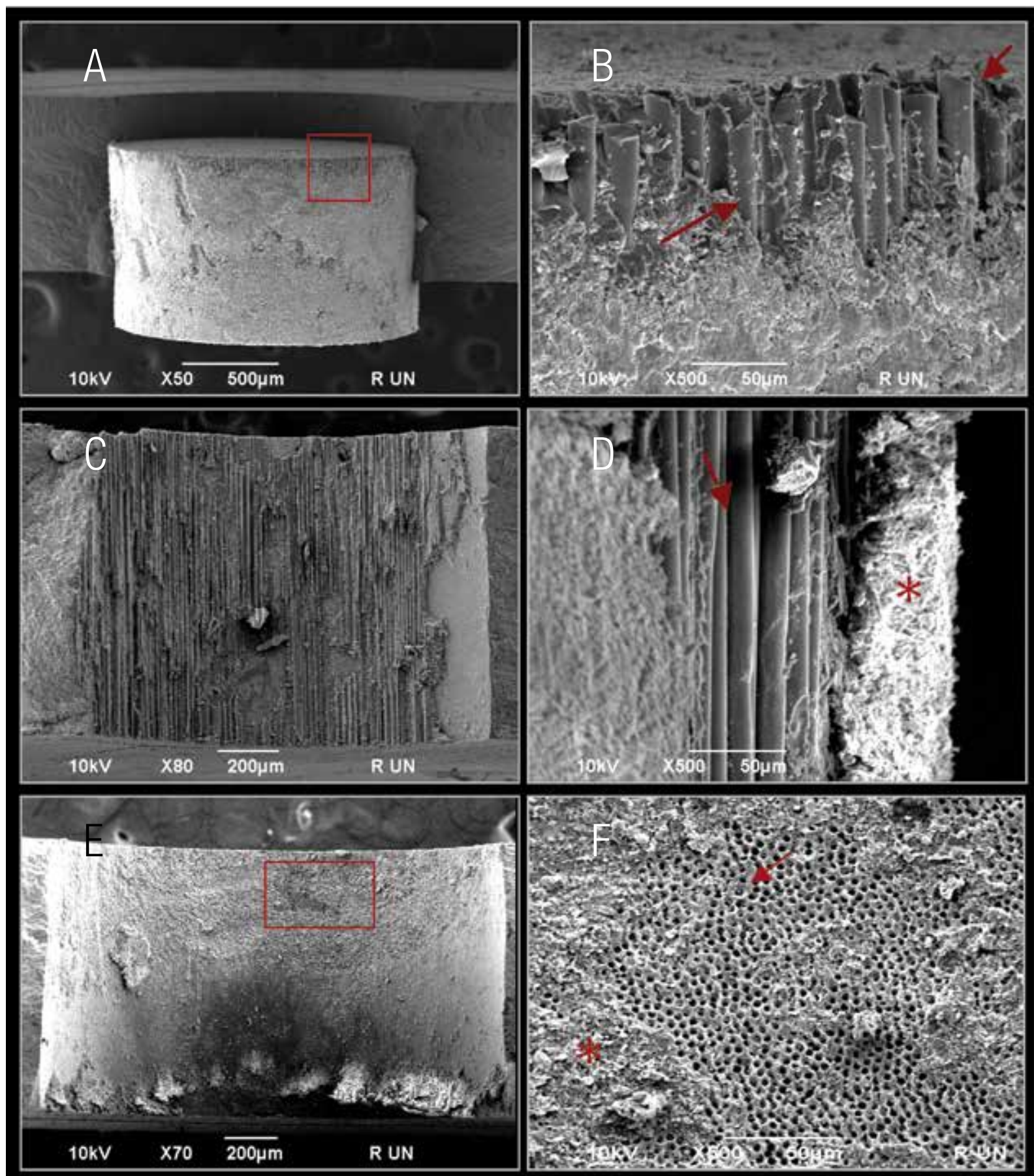

Figure 1. SEM analyses of samples luted with RelyX $X^{T M}$ Unicem (RelyXTM Unicem). In A can be observed the fiber post subjected to push-out test showing a mixed failure, and at higher magnification (B) SEM photomicrograph showed exposed post fibers (red arrows). $\mathrm{C}$ and $\mathrm{D}$ illustrate the mixed fracture pattern with fibers exposed (arrow) and areas with cement $\left(^{*}\right)$ indicating adhesive failure between the cement and dentine. In F can be observed open dentinal tubules with some areas with cement $\left(^{\star}\right)$. However, in some samples, it was possible to observe tubules plugged with cement (arrow). 


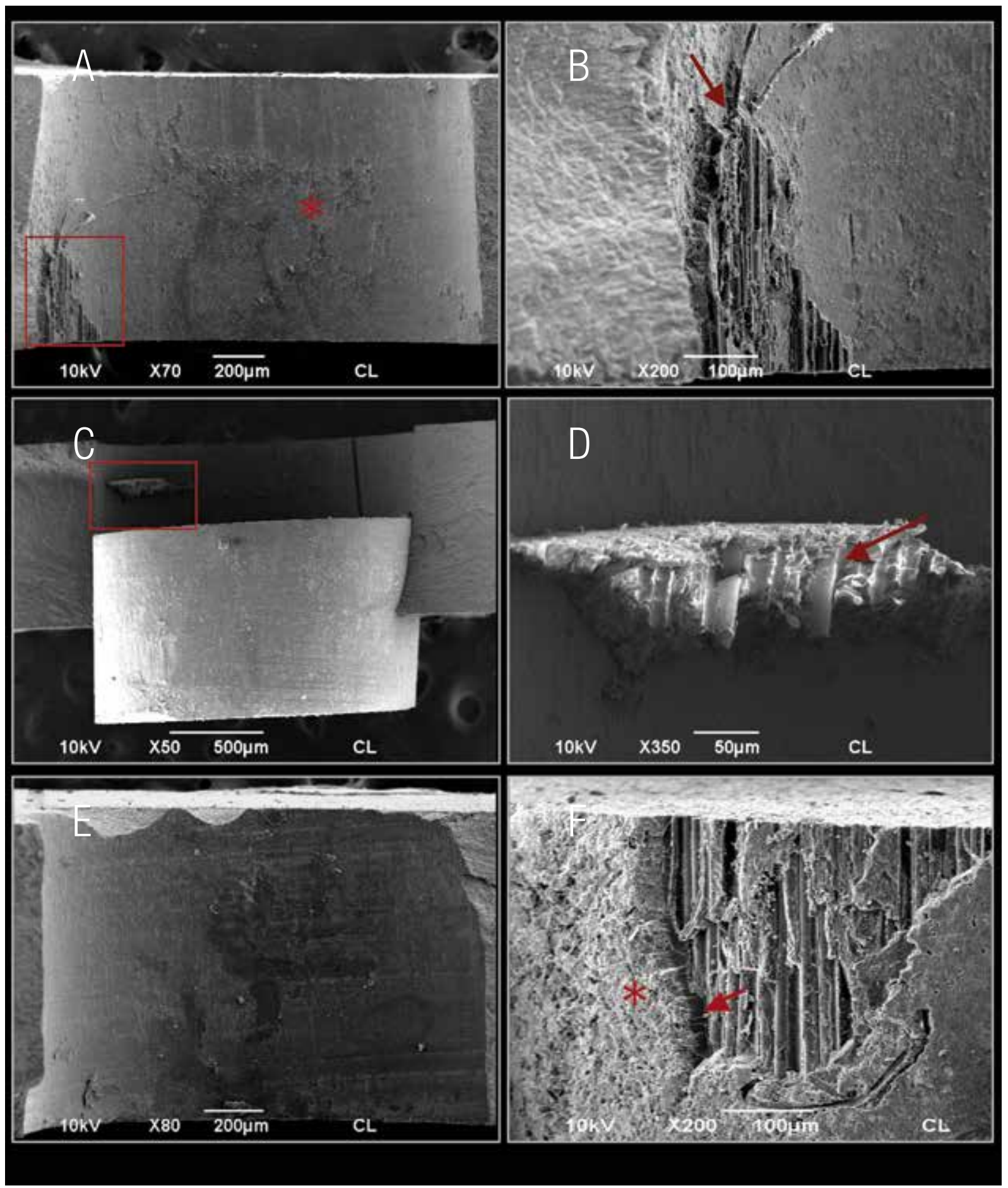

Figure 2. SEM images obtained after the push-out test of Group 2 (Clearfil TM SA). Figure A shows a mixed failure, and in B you can see the exposed post fibers (arrows) and adhered to dentin surface. $C$ and $D$ illustrate the mixed fracture pattern with some post fibers exposed (arrow). In $\mathrm{E}$ can be seen an adhesive failure between the cement and dentine. At higher magnification, in the figure $\mathrm{F}$ can be seen areas with cement $\left(^{*}\right)$ indicating adhesive failure between the cement and dentine and cohesive failure of the post (arrow). 

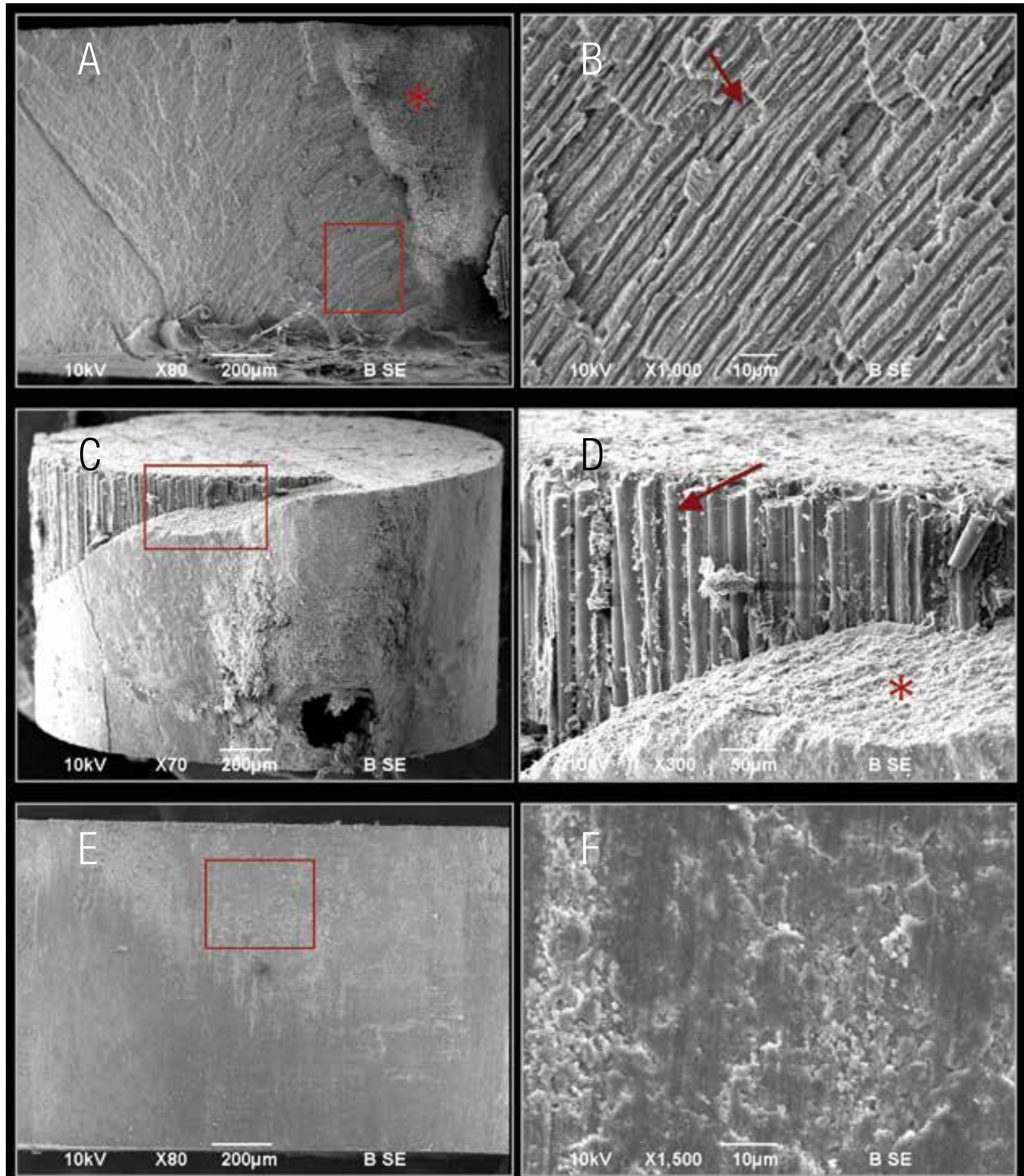

Figure 3. SEM microphotographs of Group 3 (Bifix TM SE). Figure A showed a mixed failure, and in $B$ is possible to observe adhered $t$ resin cement to the root surface (arrows). $C$ and D showed the post after its total displacement indicating failure mixed with areas with exposed fibers (arrow) and the regions showing cement ( $\left.{ }^{*}\right)$. In $\mathrm{E}$ can be observed an adhesive failure between the cement and dentine. At higher magnification in $\mathrm{F}$ in the figure showed a cement layer blocking the dentinal tubules. 

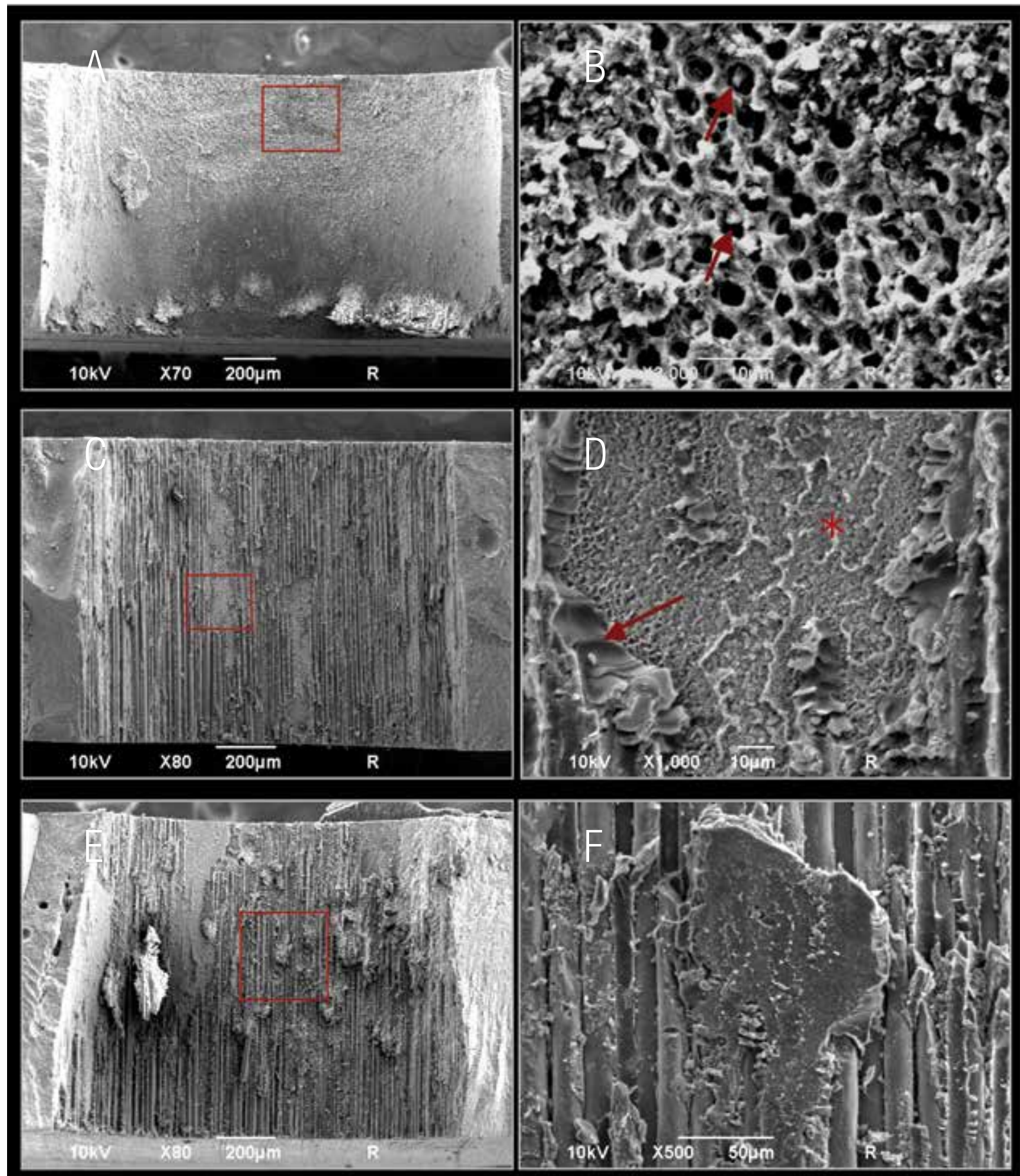

Figure 4. SEM images obtained of Group 4 (RelyX TM ARC). A showed an adhesive failure between cement and dentin, and at higher magnification of the demarcated area (B) is possible to observe the presence of resinous extensions within the dentinal tubules (arrows). In $\mathrm{C}$ and $\mathrm{E}$ can be observed a mixed failure. At higher magnification in $\mathrm{D}$ and $\mathrm{F}$ can be observed cohesive failures of the posts (arrow) and the remaining regions with cement $\left(^{*}\right)$. 

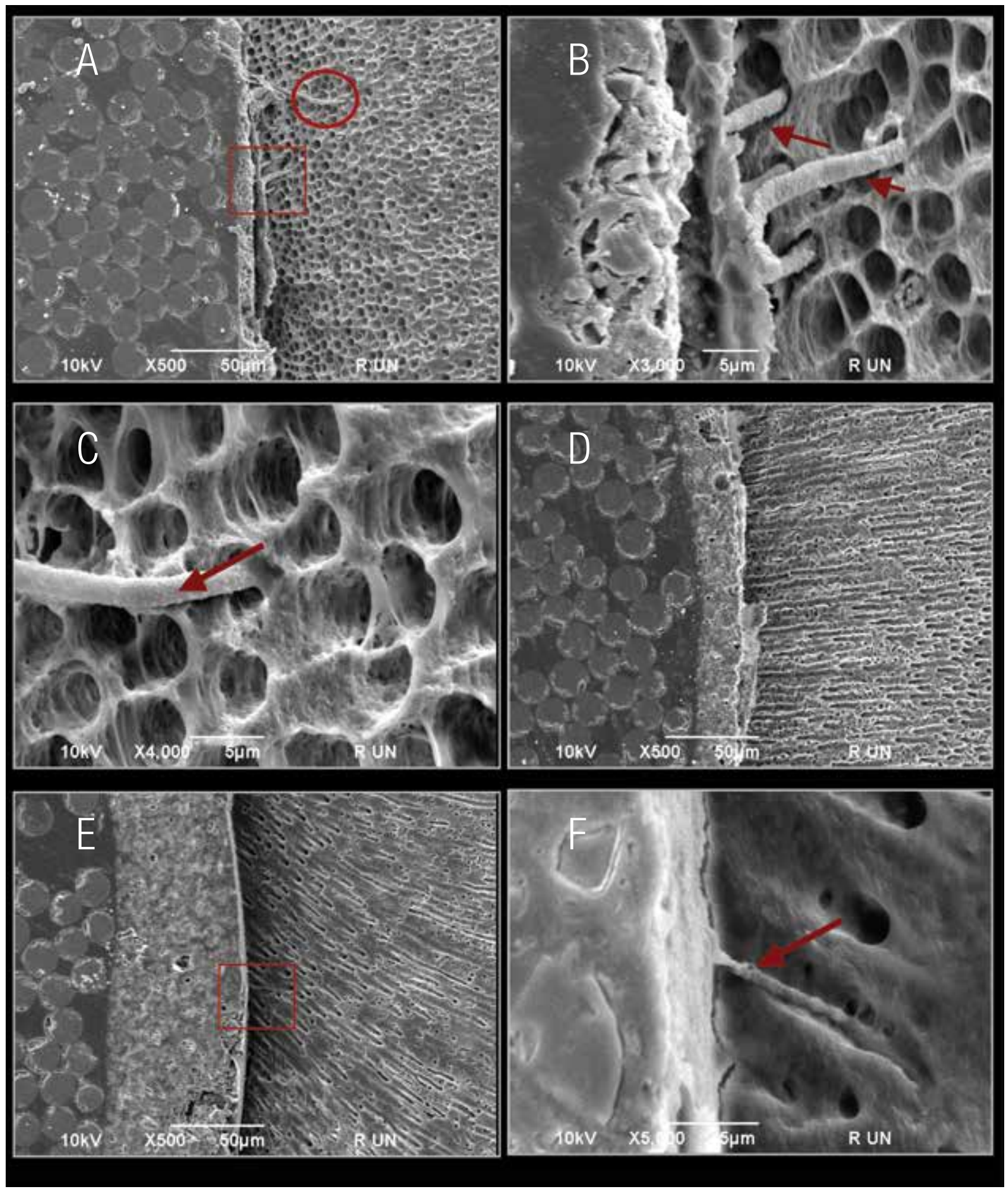

Figure 5. SEM Photomicrographs of RelyX TM Unicem / dentin interface. In Figures A and E can be observed the presence of few tags, and at higher magnification $(B, F)$ and in the circle $(C)$, it is possible to observe the formation of single resin tags, which extended to the inside of the dentinal tubules (arrows). Figure D showed an effective marginal adaptation of the cement to dentin, but without the formation of tag-like structures. 

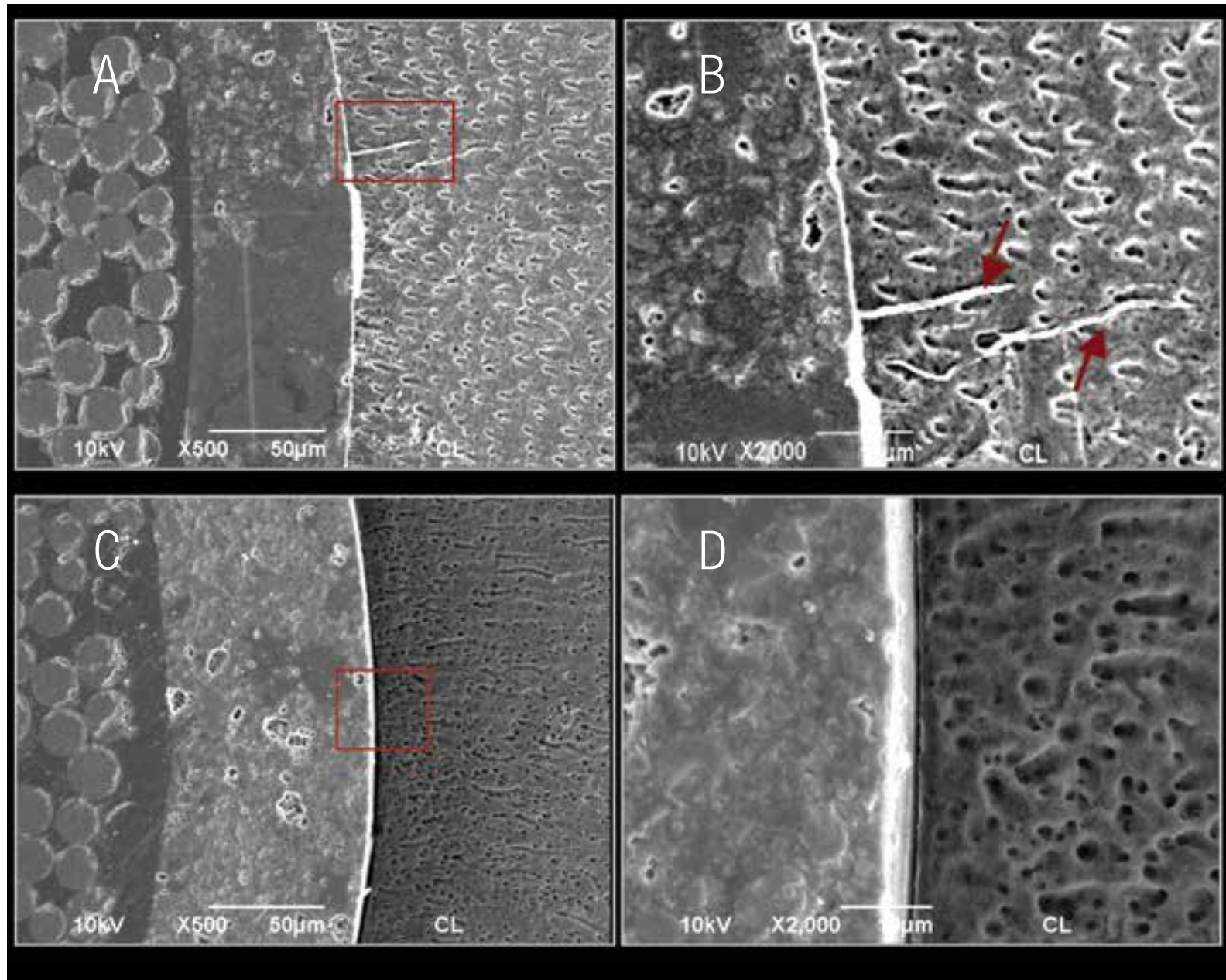

Figure 6. SEM Photomicrographs of Clearfil TM SA/dentin interface. A showed the formation of a single resin tag, suggesting that the cement penetrates into an open dentinal tubule (arrows). In $\mathrm{C}$ and $\mathrm{D}$ was observed a continuous adaptation to the dentin surface without resin tag formation. 


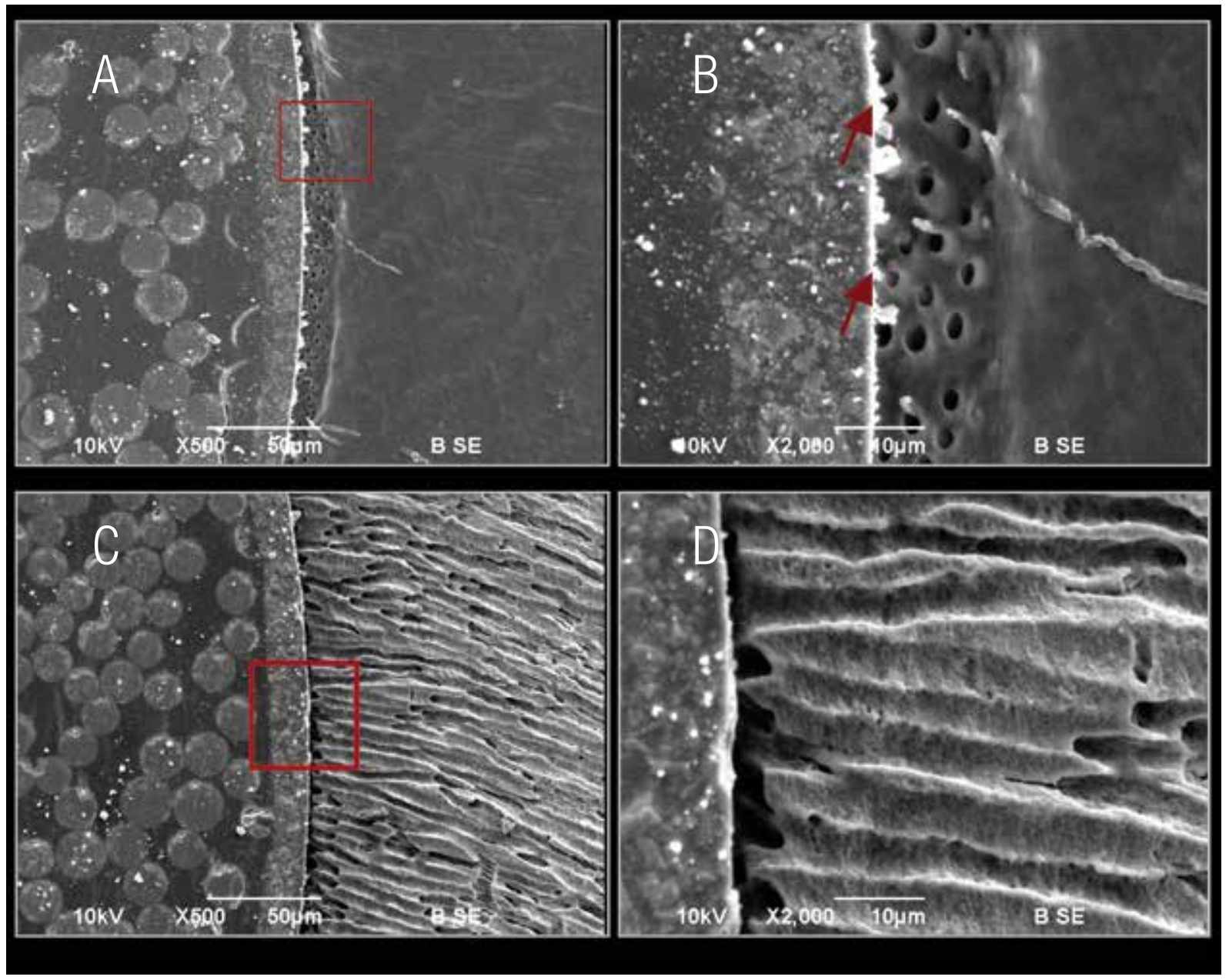

Figure 7. SEM Photomicrographs of Bifix ${ }^{\mathrm{TM}}$ SE /dentin interface. All images showed a continuous adaptation to the dentin surface without resin tag formation. 


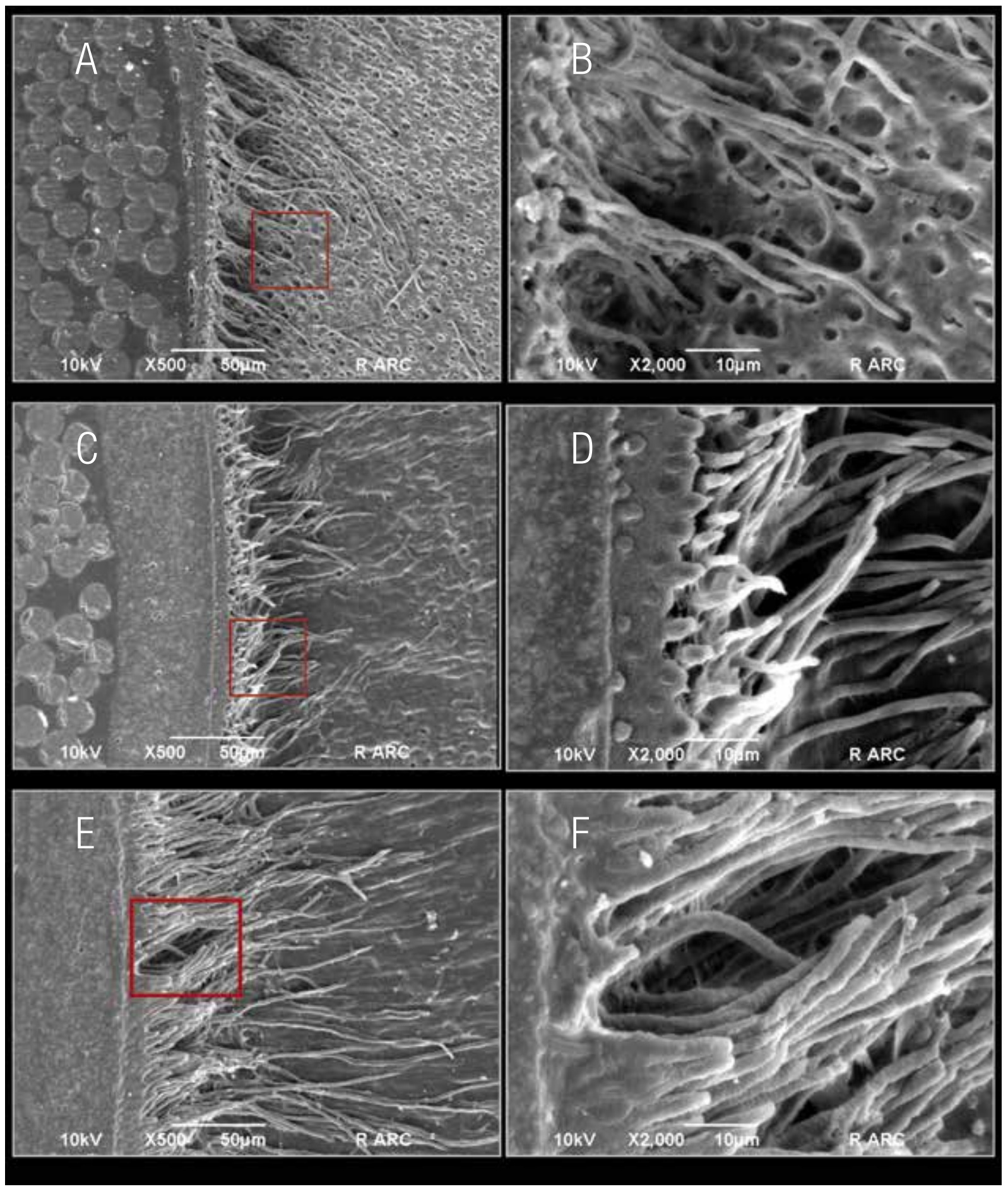

Figure 8. SEM Photomicrographs of RelyXTM ARC/dentin interface. In all images was possible to observed a continuous formation of a hybrid layer with resin tags formation. At higher magnification can be observed long resin tags with lateral branches. 


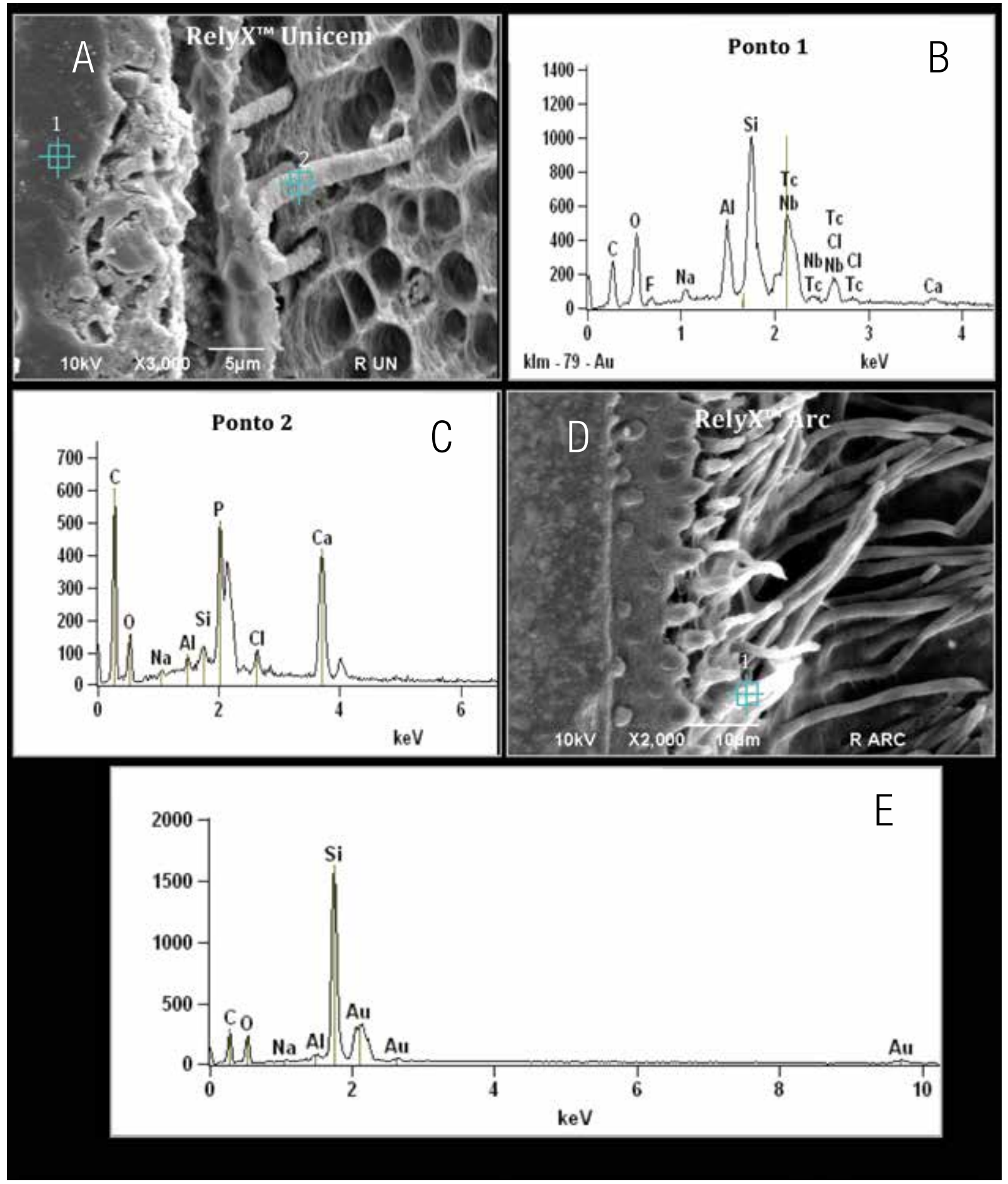

Figure 9. (A) RelyX TM Unicem/dentin interface SEM photomicrograph. (B) EDAX spectrum showing the chemical composition of the cement and of the tags structures $(C)$. Note that the tags have a different chemical composition when compared to cement, are primarily formed by calcium and phosphorus ions, suggesting that the cement promotes a chemical interaction with dentin. (D) RelyX'M ARC/ dentin interface. (E) EDAX spectrum of tags structures formed by RelyX TM ARC, demonstrates that the conventional adhesive system does not promote chemical interaction with dentin. 


\section{DISCUSSION}

The results of this study require the rejection of the null hypothesis since differences in push-out bond strength exist between the tested resin cements.

Our results showed that the samples luted with RelyX ${ }^{\mathrm{TM}}$ ARC, in association with Scotch Bond Multi-Purpose Plus, had the highest bond strength values when compared with self-adhesive resin cements. These results are consistent with previous studies in which the conventional resin cement showed a better performance $(4,7,14-16)$.

The mechanism of adhesion of conventional adhesive systems to intraradicular dentin is micromechanical in nature, by forming a hybrid layer with resin tags $(1,4,8,17-19)$. Studies have shown that three steps systems promotes a greater and more uniform interdiffusion zone with the formation of resin tags throughout the root canal (17). Apparently, greater mechanical imbrications could have a positive effect on bond strength of resin cements with dentin intraradicular (8).

Moreover, the improved performance of the conventional resin cement could be attributed to the application of the adhesive system with the aid of microbrush during the luting procedure. The use of a microbrush allows greater interdiffusion of the adhesive system within the tubules, promoting the formation of a more homogeneous hybrid layer with resin tags with similar shape and densities over the entire length of the root canal, including the apical third $(17,20)$.

Regarding the performance of self-adhesive resin cements, it was observed that RelyX ${ }^{\mathrm{TM}}$ Unicem showed higher bond strength when compared to Clearfil ${ }^{\mathrm{TM}}$ SA and Bifix SE. Self-adhesive resin cements were recently introduced in clinical practice and have been presented as an innovative alternative to conventional resin cements. These materials congregate into one product the ability of self-adhesion, the property of release fluoride ions as glass ionomer cements, combined with a less sensitive operative protocol (8). Unlike conventional resin cements, self-adhesive cements do not require any pretreatment on the tooth substrate (8).

The mechanism of action of self-adhesive resin cements produce a micro-mechanical retention and a chemical interaction between the acidic monomers of the cement and the hydroxyapatite of dentin (8). Although the adhesion mechanism should be similar for all self-adhesive cements, the main properties of RelyX'M Unicem are the most studied and explained by the manufacturer. Its multifunctional monomers with the phosphoric acid groups, desmineralize and infiltrate dentin, simultaneously (8). The dominant setting reaction is the radical polymerization which can be initiated by light exposure or through self cure mechanisms (21). Moreover, to ensure the neutralization of this acidic system, a glass ionomer concept was applied, resulting in an $\mathrm{pH}$ increase through reactions between phosphoric acid groups and alkaline components $(8,21)$. This acid-base reaction releases water, which favors the hydrophilic behavior of the material in the initial reaction, providing a better adaptation with the tooth structure and a higher tolerance to moisture. Subsequently, water is expected to be re-used by the reaction of acidic functional groups and during the cement reaction with ion-releasing basic filler particles. This reaction eventually results in a chemical interaction with hydroxyapatite $(8,21$, 22). However, it does not detect a clear balance between the degree of demineralization and infiltration of self-adhesive resin cement $(8,21)$.

Additionally, is important to highlight that the acidity of the monomers may facilitate the infiltration of composite in the dental substrate, however an inadequate neutralization of these monomers can affect the polymerization of the material $(8,21)$. Thus, it is likely that the different bond strength values obtained by RelyX ${ }^{\mathrm{TM}}$ Unicem 
and their counterparts Clearfil ${ }^{\mathrm{TM}}$ SE and Bifix SA may be attributed to differences in their chemical composition, and its possible effect on the reaction between acid and basic groups, impairing the polymerization of the cement and, consequently, their physical and mechanical properties. However, further studies are required in order to evaluate the chemical composition of the different cements and its effect on the mechanism of action of selfadhesive cements.

Unlike conventional resin cements, SEM photomicrographs of samples luted with selfadhesive cements showed a continuous interface, characterizing the interaction of the material with dentin. Hybridization of dentin was only detected sporadically for the self-adhesive resin cement RelyX'M Unicem. This finding corroborates the results of investigations conducted previously that also described a superficial morphological interaction $(3,23,24)$. In the present investigation, penetration of this cement into the dentinal tubules was found in only one specimen. Thus, it can be concluded that the smear layer did not dissolve consistently at the dentin-RelyX Unicem interface. The rapid rise in $\mathrm{pH}$ could also affect the demineralization effect of this material $(1,25)$.

Although in this study the highest bond strength values were obtained with the conventional resin cement, it should be noted that the chemical interaction between self-adhesive cement and hydroxyapatite may be more important over time in terms of adhesion with intraradicular dentin that hybridization of dentin, as previously suggested by Bitter et al. (1). However, further studies are required to assess the bond strength over time of these materials, as well as assessing their clinical performance.

The analysis of failure modes revealed that the predominantly failure mode was adhesive between dentin and cement, which is in accordance with previous studies $(1,26)$. This result suggest that the interaction between factor- $\mathrm{C}$ of the root canal space and the polymerization shrinkage of conventional and self-adhesive resin cements may have resulted in unfavorable conditions for fiber posts adhesive luting procedures.

Regarding the root region, there is much controversy in the literature about whether there was difference in adhesion between post and cement in the different radicular thirds. Each region had different distribution and density of dentinal tubules. These densities decreased significantly from cervical to the apical third $(6$, 18), and could be directly related to the bond strength values achieved in this study. All groups in this study showed higher values in the cervical third, while the lowest were found in apical third. These results are consistent with other studies that have revealed regional differences in bond strength $(5,16)$.

Based on the results of this study we concluded that the conventional resin cement associated with a three-step adhesive system displayed the higher bond strength to intraradicular dentin, when compared to the different selfadhesive resin cements tested.

\section{REFERENCES}

1. Bitter K., Paris S., Pfuertner C., Neumann K., Kielbassa A. M. Morphological and bond strength evaluation of different resin cements to root dentin. Eur J Oral Sci, 2009; 117; 326-333.

2. Schwartz R. S., Robbins J. W. Post placement and restoration of endodontically treated teeth: a literature review. J. Endod, 2004; 30: 289-301.

3. Goracci C., Sadek F. T., Fabianelli A., Tay F. R., Ferrari M. Evaluation of the adhesion of fiber posts to intraradicular dentin. Oper Dent, 2005; 30: 627-635.

4. Goracci C., Tavares A. U., Fabianelli A., Monticelli F., Raffaelli O., Cardoso P. C., 
Tay F., Ferrari M. The adhesion between fiber posts and root canal walls: comparison between microtensile and push-out bond strength measurements. Eur J. Oral Sci, 2004; 112: 353-361.

5. Bitter K., Meyer-Lueckel H., Priehn K., Kanjuparambil J., Neumann K., Kielbassa A. M. Effects of luting agent and thermocycling on bond strengths to root canal dentine. Int Endod J, 2006; 39: 809-818.

6. Bouillaguet S., Troesch S., Wataha J. C., Krejci I., Meyer J. M., Pashley D. H. Microtensile bond strength between adhesive cements and root canal dentin. Dent Mater, 2003; 19: 199-205.

7. De Durao Mauricio P. J., Gonzalez-Lopez S., Aguilar-Mendoza J. A., Felix S., GonzalezRodriguez M. P. Comparison of regional bond strength in root thirds among fiberreinforced posts luted with different cements. J. Biomed Mater Res B Appl Biomater, 2007; 83: 364-372.

8. Ferrari M. Fiber posts and endodontically treated teeth: a compendium of scientific and clinical perspectives. Wendywood: Modern Dentistry Media; 2008. p.85-93.

9. Monticelli F., Osorio R., Mazitelli C., Ferrari M., Toledano M. Limited decalcification/ diffusion of self-adhesive cements into dentin. J. Dent Res, 2008; 87: 974-979.

10. De Munck J., Vargas M., Van Landuyt K., Hikita K., Lambrechts P., Van Meerbeek B. (2004). Bonding of an auto-adhesive luting material to enamel and dentin. Dent Mater; 20: 963-971.

11. Ibarra G., Johnson G. H., Geurtsen W., Vargas M. A. (2007). Microleakage of porcelain veneer restorations bonded to enamel and dentin with a new self-adhesive resin-based dental cement. Dent Mater; 23:218-225.

12. Mazzitelli C., Monticelli F. Evaluation of the push-out Bond strenght of self-adhesive resin cements to fiber posts. International dentistry, 2010; 11: p. 54-60.

13. Perdigao J., Van Meerbeek B., Lopes M. M., Ambrose W. W. The effect of a re-wetting agent on dentin bonding. Dent Mater, 1999;15: 282-95.

14. Wang V. et al. Effect of two fiber post types and two luting cement systems on regional post retention using the push-out test. Dent Mater, 2008; 3: 372-7.

15. Kececi A. et al. Micro push-out bond strenghts of four fiber-reinforced composite post systems and 2 luting materials. Oral Surg. Oral Med. Oral Pathol. Oral Radiol. Endod., 2008; 1: 121-8.

16. Ferrari M. et al. Influence of luting material filler content on post cementation. J. Dent. Res, 2009; 10: 951-6.

17. Ferrari M., Vichi A., Grandini S. Efficacy of different adhesive techniques on bonding to root canal walls an SEM investigation. Dent Mater, 2001; 5: 422-29.

18. Ferrari $M$ et al. Bonding to root canal: Structural characteristics of the substrate. Am J. Dent, 2000; 5: 255-60.

19. Bitter K. et al. Bond strengths of resin cements to fiber-reinforced composite posts. Am J. Dent, 2006; 2: 138-42.

20. Ferrari, M. et al. Influence of microbrush on efficacy of bonding into root canals. Am J Dent, 2002; 15: 227-31.

21. Radovic I. et al. Coupling of composite resin cements to Quartz fiber posts: a comparison of industrial and chairside treatments of the post surface. J Adhes. Dent, 2008; 1:57-66.

22. GERTH, H.U. et al. Chemical analysis and bonding reaction of RelyX Unicem and Bifix composites--a comparative study. Dent Mater., Washington, v. 22, n.10, p. 934-41, Oct. 2006.

23. Al-Assaf K., Chakmakchi M., Palaghias G., Karanika-Kouma A., Eliades G. Interfacial 
characteristics of adhesive luting resins and composites with dentine. Dent Mater 2007; 23: 829-839.

24. De Munck J., Vargas M., Van Landuyt K., Hikita K., Lambrechts P., VanMeerbeek B. Bonding of an auto-adhesive luting material to enamel and dentin. Dent Mater 2004; 20: 963-971.
25. Saskalauskaite E., Tam L. E., Mccomb D. Flexural strength, elastic modulus, and $\mathrm{pH}$ profile of self-etch resin luting cements. J Prosthodont 2008; 17: 262-268.

26. Zicari F., Couthino E., De Munck J., Poitevin A., Scotti R., Naert I., Van Meerbeek B. Bonding effectiveness and sealing ability of fiber-post bonding. Dent Mater 2008; 24: 967-977. 